\title{
Animal board invited review: precision livestock farming for dairy cows with a focus on oestrus detection
}

\author{
T. Mottram ${ }^{\dagger}$ \\ Royal Agricultural University, Cirencester GL7 6JS, England
}

(Received 31 March 2015; Accepted 9 October 2015; First published online 26 November 2015)

\begin{abstract}
Dairy cows are high value farm animals requiring careful management to achieve the best results. Since the advent of robotic and high throughput milking, the traditional few minutes available for individual human attention daily has disappeared and new automated technologies have been applied to improve monitoring of dairy cow production, nutrition, fertility, health and welfare. Cows milked by robots must meet legal requirements to detect healthy milk. This review focuses on emerging technical approaches in those areas of high cost to the farmer (fertility, metabolic disorders, mastitis, lameness and calving). The availability of low cost tri-axial accelerometers and wireless telemetry has allowed accurate models of behaviour to be developed and sometimes combined with rumination activity detected by acoustic sensors to detect oestrus; other measures (milk and skin temperature, electronic noses, milk yield) have been abandoned. In-line biosensors have been developed to detect markers for ovulation, pregnancy, lactose, mastitis and metabolic changes. Wireless telemetry has been applied to develop boluses for monitoring the rumen $\mathrm{pH}$ and temperature to detect metabolic disorders. Udder health requires a multisensing approach due to the varying inflammatory responses collectively described as mastitis. Lameness can be detected by walk over weigh cells, but also by various types of video image analysis and speed measurement. Prediction and detection of calving time is an area of active research mostly focused on behavioural change.
\end{abstract}

Keywords: dairy cow, sensors, fertility, precision livestock farming, automation

\section{Implications}

Since the introduction of robotic milking technologies to measure important parameters of cow health and fertility have moved from scientific concepts towards robust techniques routinely used on farms. There is still potential for developing new approaches but the main focus is on applying modelling to data sources that are already available such as tri-axial cow collars, in-line milk sensing and rumen telemetry.

\section{Introduction}

In the past century dairy farms have become larger, milk yields have risen, quality requirements have risen, labour has become less available and automated systems for milking and other farm tasks have become common all of these factors have created a need for automated monitoring of health and fertility. The first systems for recording milk yield electronically and allocating feed date back to the 1970s and automatic oestrus behaviour systems from the 1980s. As electronics have become

${ }^{\dagger}$ E-mail: toby.mottram@rau.ac.uk cheaper and new sensing capabilities developed a variety of engineering options were reviewed for all animals by Frost et al. (1997). Mottram (1997) reviewed potential target disease conditions in dairy cows and identified parturition, mastitis and failures in nutrition as the most significant causes of loss. It was suggested that sensing should focus on the most directly measurable indicator of a condition such as rumen $\mathrm{pH}$ rather than proxy measures. Since then major developments have taken place in radio identification of animals (electronic identification (EID)) by ear tag and bolus with ISO 11784:1996 (last reviewed in 2010) making it easier to associate data with individual animals.

This review focuses on the new technical capabilities and research in progress as well as new systems in the early stage of market development to detect the most costly events (fertility, calving and some diseases). The evaluation of the benefits and costs of new technology were well evaluated by Bewley et al. (2010). For space reasons this review omits measurements such as milk constituents and rumination, since these are mostly aimed at improving the performance of healthy cows rather than detecting disease although they will do that by exception. 


\section{Oestrus detection}

The calving index or numbers of days between calving has been steadily rising since the introduction of artificial insemination at about 1 to 2 days/year and in 2009 it was 420 days in the United Kingdom (DairyCo.org.uk). A number of studies summarised by Boyd (1992) showed 95\% of cows had active ovaries. As milk yields have risen and body condition declined with more extreme Holstein breeds the number may now be lower, $71 \%$ was measured by Lopez et al. (2005), so failure to observe oestrus is the most important factor preventing higher conception rates. Claus et al. (1983) measured progesterone in milk fat in 123 cows from a number of farms to determine factors influencing fertility. The greatest influence on the cow fertility was management, with $32 \%$ of cycles detectable by progesterone not being recognised by the herdsman. Between $5 \%$ and $21 \%$ of cows were inseminated at the incorrect time in the cycle.

A wide variety of techniques and devices have been proposed and tested to improve oestrus detection. However, this review assumed that there could only be a limited role for devices that need to be inserted into the cow either surgically or into the vagina; these devices were reviewed by Senger (1994) and they have little market presence.

\section{The oestrus cycle}

The sequence of events associated with the ovarian cycle in dairy cows is well known and described in a number of standard texts such as Peters and Ball (1995). For the purposes of detection of the stage of the ovarian cycle the cow may emit a number of hormonal and behavioural signals, which may be measured externally. Progesterone levels are elevated from 4 to 16 days post-ovulation then fall to a nadir. The hormone oestradiol has an inverse relationship to progesterone so that as progesterone levels fall that of oestradiol rises. The oestradiol stimulates the oestrus behaviour which is most commonly used to select cows for insemination. The optimum time to inseminate the cow is 6 to $12 \mathrm{~h}$ after the peak in oestradiol concentration. Schofield (1988) describes diurnal peaks of oestrus behaviour early in the morning and late at night. However, he showed that standing to be mounted was not a reliable indicator of a cow being suitable to be served, with as many as $21 \%$ of ridden cows were pregnant. Warren (1984) surveyed 35000 cows in 255 herds and showed that $26 \%$ of interservice intervals were $>48$ days and that $19 \%$ of cows were served at an interval of 1 to 17 and 25 to 35 days suggesting that one or other of the observed oestrus events was not accompanied by ovulation whose periodicity has been established as very consistent. Frequently the performance of a device is compared with the ability of the herdsman to observe behavioural indications of oestrus. A more satisfactory reference to use is milk or blood progesterone level, which gives a reliable indication of ovulation.

\section{Oestrus: mount detectors}

Stevenson et al. (1996) report the use of an electronic, radiotelemetric, pressure-sensitive, rump-mounted device, which was designed to be activated by the weight of a mounting animal. The sensor sent a signal by radio to a computer that recorded the mounted animal's identification, date, time and duration of the mounting. An experiment was carried using 49 peripubertal, crossbred yearling beef heifers with synchronised oestrus. The heifers were inseminated after oestrus was detected, or after a fixed interval if oestrus was not detected. The performance of the sensor system was compared with conventional observation (for $45 \mathrm{~min}$ at 0730 and $1630 \mathrm{~h}$ ). Observation detected 30 heifers, all of which were also detected by the device. The device detected an additional 11 heifers which were not detected by observation. Neither method detected oestrus for the remaining eight heifers although two of these conceived. One development of the historic dye patch system is to use a camera system to automatically measure whether the heat patch has been triggered (Hempstalk et al., 2013) and despite some initial problems ensuring that cameras were correctly set up achieved an acceptable correlation to herdsmans observations mapped to progesteron analysis. The high level of success of the herdsman in detecting oestrus in this experiment with 797 cows (over $80 \%$ ) indicates a commercial herd with very good results without automation.

\section{Oestrus: pedometers}

Pedometers are electronic devices that are strapped to a cow's leg to count steps. The older designs contain an electrical switch which opens or closes when the device is moved. Each activation of the switch adds to a count in the pedometer. The total count is transferred to a base station by telemetry when the cow is in the vicinity of a receiver unit. Since the number of movements counted by a pedometer has no absolute significance, it is necessary to establish a comparative technique in which a count is compared with a baseline count, which would be expected from the cow if it were not exhibiting oestrus. If a count exceeds the baseline by some predetermined multiplier, the cow is deemed to be in oestrus. The main variables involved in this process are therefore how frequently the total counts are transferred to the base station (this is often twice a day at milking), and the multiplier that is used to set the oestrus alert threshold. The Alpro from de Laval sends a signal to the base station whenever it detects a rise above threshold. There have been many studies aimed at assessing the effectiveness of pedometers. For example Peter and Bosu (1986) carried out a trial with 47 cows at pasture. Pedometer readings were taken twice a day at milking. No details are given of the alert threshold that was used, but $76 \%$ of ovulations were detected by pedometer, compared with $35 \%$ by herdsman observation (30 min twice a day). All of the cases that were detected by the herdsman were also detected by the pedometers. The reference method for ovulation detection was measurement of blood progesterone concentration.

Koelsch et al. (1994) used pedometers on 21 cows. The reference method was milk progesterone level. Various methods of analysing the pedometer data were tried. The most successful method, which involved several stages of 
data processing, provided a specificity (SP) of $99 \%$ but a sensitivity (SN) of only $69 \%$. The highest sensitivity of any of the attempted methods was $76 \%$, and this was at the expense of a reduced specificity of $94 \%$. It is important to note that the procedure was tested on the same data that were used to develop it, so the performance of the method on a fresh set of cows (or even a fresh set of data from the same set of cows) is unknown. All of the above studies support the general conclusion that pedometers are not capable of providing completely reliable ovulation detection. If a specificity of close to $100 \%$ is required (i.e. a minimal number of false positives) the associated sensitivity (the proportion of ovulating cows that are detected) is generally $<70 \%$. There are at least two possible reasons for this less than ideal performance. One is that activity is not a totally reliable indicator of ovulation, and the second is that the pedometer is not totally reliable method of registering the relevant activities. Van Vliet and Van Eerdenburg (1996) investigated these two possibilities. They fitted pedometers to 37 non-pregnant cows among the herds on two dairy farms. The total number of cows on the two farms was about 100. They also observed the behaviour of the 37 cows for periods lasting $30 \mathrm{~min}$ at $2 \mathrm{~h}$ intervals for 6 weeks. This very careful observation resulted in ovulation detection with a sensitivity of $74 \%$ and a specificity of $100 \%$. Step counting is not reliable as an indicator of ovulation as about $20 \%$ of cows do not exhibit the behaviours.

\section{Oestrus: detection with collars}

Collars for detecting oestrus have been available since the early 1980s. The early versions used simple mercury tilt switches or rolling balls to count the number of head movements. These were relatively expensive devices until the integrated circuits with tri-axial accelerometers became available in the 1990s. Since the advent of cheap tri-axial accelerometers and digital signal processor chips the collar has been shown as a tool that can not only detect oestrus but also lying behaviour, lameness, location, and with the collection of audio data rumination and eating activities. These collars have been used widely and models are slowly emerging as to how the data can be integrated into a wholistic management system. Commercial activity has probably been more advanced than research reports. The Voronin et al. (2011) invention provided a method and device for detecting oestrus in animal by sensing along time the motion of the animal and identifying when the sensed motion is not related to eating periods of the animal. Kamphuis et al. (2012) had similar results to those with pedometers and achieved $76.9 \%$ SN, 99.4\% SP and $82.4 \%$ positive predictive value (PPV). While activity only collars achieved $62.4 \%$ SN, 99.3\% SP and 76.6\% PPV all in comparison with progesterone analysis of milk as the gold standard. This and other patents in this area shows over 50 listed each attempting improvements on the basic concept.

\section{Oestrus: milk temperature}

A cow's body temperature rises at oestrus. A non-invasive method of oestrus detection is to measure the milk temperature in the claw piece or short milk tube of the milking system. Maatje et al. (1987) carried out two experiments; one with 28 housed cows, and one with 20 cows that were grazing during the day and housed at night. Oestrus was assumed to be associated with a significant (twice the standard deviation of the temperature during the previous 5 days) rise in milk temperature, compared with the average temperature over the 5 previous days. This produced an oestrus detection sensitivity of $74 \%$, with a false rate of $8 \%$, using milk progesterone as the reference technique. McArthur et al. (1992) have also examined the reliability of this method. They made measurements under experimental, controlled conditions, and under commercial conditions. The milk temperature of the two cows studied under controlled conditions rose by about $0.4^{\circ} \mathrm{C}$ on the day when behavioural oestrus was observed. On a commercial farm milk temperatures were measured for 18 cows, which exhibited a total of 34 periods of oestrus. Setting a threshold of $0.3^{\circ} \mathrm{C}$ elevation in temperature over the average for the previous 5 days resulted in a oestrus detection sensitivity of $50 \%$ with an associated false positive rate of $81 \%$. Increasing the threshold elevation to $0.6^{\circ} \mathrm{C}$ resulted in a reduction in the false rate to $65 \%$, but a reduction in sensitivity to $32 \%$. McArthur et al., compared their results with those from other studies that show wide ranges of sensitivity and false rates. They observe that, although some of these have reported better results, the only other study that was carried out, like theirs, in a commercial herd, produced similar results (sensitivity about $40 \%$ with $70 \%$ false positives). McArthur et al. also made measurements of vaginal temperature which showed that the temperature increase associated with oestrus only lasts about $9 \mathrm{~h}$. They concluded that the shortness of this period, which can be less that the interval between milkings, contributes towards the uncertainty of oestrus detection. The conclusion from McArthur et al. is that the detection of oestrus based on twice daily measurement of milk temperature is not reliable and no further reports have been found.

\section{Oestrus: milk yield}

Blanchard et al. (1987) and Schofield et al. (1991) have suggested that the continuous monitoring of milk yield can indicate oestrus. However, these patterns have not proved sufficiently specific and this approach has been abandoned except in robotic milking where it can be combined with other data (number and timing of visits).

\section{Oestrus: skin temperature}

Hurnik et al. (1985) investigated the possibility of using thermal IR scanning of the body surfaces of a cow to detect temperature changes related to ovulation. The study was conducted using 27 cows, housed in tie stalls. A thermal imaging device, comprising a temperature sensing camera and a video display, was used to take images of the gluteal region of the cow, including the anal and vulval areas, the posterior zone of the udder attachment and the two posterior lobes of the udder. According to the specification of the 
imaging system, it was possible to resolve differences of $0.2^{\circ} \mathrm{C}$. The images were analysed by measuring the total area of the cow that was enclosed in a given $37^{\circ} \mathrm{C}$ isotherm. Using a criterion based on a given percentage increase in this area, the ovulation detection sensitivity was $80 \%$, but this was associated with a false rate of $33 \%$. The conclusion was that high frequency of false positives and false negatives meant that the technique was not suitable for routine oestrus detection. Since this paper was written there have been improvements in thermal imaging equipment, but the difficulty of eliminating or accounting for non-oestrus related temperature variation caused by factors such as environmental temperature variation, and moisture on the skin, remain. Considering also the inherent complexity of the system it seems very unlikely that the thermal imaging approach will yield a reliable, practical automatic oestrus detection system although Future Dairy (2012) investigated the technique.

\section{Oestrus: combined measures}

Maatje et al. (1997) report a multivariate oestrus detection model which bases detection on a combination of activity (measured by pedometer), milk temperature, yield and feed intake. Using data from two experimental farms, which included over 500 cases of oestrus, they achieved a detection sensitivity of $87 \%$ with a specificity of $97 \%$. This represented an improvement in sensitivity, with equal specificity compared with results obtained using activity alone. Mitchell et al. (1996) have carried out a preliminary investigation of the possibility of combining milk yield and data on milking order to detect oestrus. These variables were chosen because of appropriateness for New Zealand dairy herds. The proposition was that since at oestrus milk volumes sometimes fall and then rise at the next milking and the order in which cows present themselves to be milked changes, it may be possible to use a computer to recognise characteristic patterns in the data. Two different machine learning procedures (C4.5 and FOIL) were tried on a year's data from a herd of 130 cows. The best result that was achieved was a sensitivity of $69 \%$, with an associated false positive rate of $74 \%$. Fundamental questions regarding the nature of cow performance variations at and around oestrus remained to be answered. It was suggested that performance could be improved by including more monitored variables. Intuitively one might expect results to improve as the number of variables that are included increases. However, the increased complexity of the system particularly if it involves adding extra sensors and the difficulty of fusing the various sets of data has to be overcome. This effectively requires an appropriate weighting to be given to the data from each source. For example, one set of data, say pedometer readings, might, if taken alone, indicate oestrus, whereas another set of data, say milk temperature, does not indicate oestrus. The combined system would be required to attach relative levels of confidence to the two indications to produce a decision. There are established techniques available for data fusion, but whether any of them would be suitable for this application has yet to be investigated.

\section{Oestrus: electronic nose}

The natural method of oestrus and relies on a combination of senses, olfactory, visual and auditory. The existing methods reviewed in the previous sections all rely on visual signs but there now exists the potential to detect olfactory signals electronically. Kiddy et al. (1984) trained dogs to identify different bottles containing suitable body compounds of dairy cows and concluded that odours specific to oestrus were distributed throughout the body. Blazquez et al. (1988) showed that pheromonal odour secreted from the perineal glands near the vagina was the determinant of bull behaviour towards the cows. However, they could not identify the compounds responsible or whether it was an increased rate of secretion that was important. Klemm et al. (1987 and 1994) steadily developed an understanding of the odours secreted in vaginal mucus. They identified acetaldehyde as a compound associated with oestrous although this is not a specific marker for oestrous and the identity of the pheromone was not determined. Llobet et al. (1999) indicated that an array of tin oxide sensors could discriminate between oestrus and di-oestrus from the odour of vaginal swabs but not from air samples taken from the surface of the cow. A subsequent study did not produce encouraging results (Mottram et al., 2000).

\section{Oestrus: progesterone assay}

Most experiments to measure the efficacy of oestrus detection systems use progesterone assay as the standard calibration tool. A sample of milk is taken and analysed once per day first to identify that oestrus cycling has begun and then to identify the drop in progesterone which precedes ovulation by $\sim 48 \mathrm{~h}$. Nebel (1988) reviewed the development of the immuno-sensing tests for progesterone. The principle of these tests is that an antibody to progesterone is attached to a plastic surface during manufacture. The farmer or veterinarian then adds milk. Progesterone in the milk then attaches to the antibody coated on the surface. A reagent is added and rinsed out and a colour change is observed to identify the amount of progesterone present in the milk. Analysis of progesterone levels in milk can not only be used to monitor the stage of the oestrous cycle but also to detect pregnancy and to identify early ovarian disorders (Macleod and Williams, 1991; Darwash and Lamming, 1996). Taking and analysing milk samples away from the milking parlour is labour intensive, strategies have been needed to minimise the number of samples needed to improve fertility. Experimental work during the 1980s established a sampling protocol and showed that inseminating cows on the basis of progesterone profiles using laboratory analysis of samples could achieve significant improvements in fertility. The protocol used by McLeod and Williams (1991) showed that $99 \%$ of 88 ovulations were correctly identified using on-farm progesterone kits compared with $78 \%$ in a control group monitored conventionally. Milk samples were taken three times a week starting 25 days postpartum. Once an ovulation had been detected by a fall in progesterone concentration to below $4 \mathrm{ng} / \mathrm{ml}$ and a subsequent rise to $>7 \mathrm{ng} / \mathrm{ml}$ sampling 
was suspended for 15 days. Sampling resumed on alternate days until a fall in progesterone indicated the onset of oestrus. The cows were then inseminated $48 \mathrm{~h}$ following the fall in progesterone. Sampling continued so as to determine whether oestrus had been correctly identified or whether the cow had conceived.

The protocol used by McLeod and Williams (1991) was also used to detect ovarian malfunction. A study of over 500 cows in a controlled trial suggested that alternate day progesterone profiles were a better method of analysing ovarian malfunction than rectal palpation. This study confirmed other results and showed that there was little incidence of ovarian dysfunction and that the principal cause of extended calving intervals was a failure to detect oestrus. Cows were diagnosed as anoestrus - when progesterone was below $4 \mathrm{ng} / \mathrm{ml}$ for 30 days postpartum. Ovulation was deemed to have occurred if progesterone was below $4 \mathrm{ng} / \mathrm{ml}$ followed by 5 days of progesterone rising above $4 \mathrm{ng} / \mathrm{ml}$, with at least one sample $>7 \mathrm{ng} / \mathrm{ml}$. Normal cycling was detected by an increase of progesterone that remained high for $>5$ days and $<18$ days. If progesterone increased in the 2 to 6 days following insemination then the insemination was assumed to be correctly timed. Conception was identified if ovulation and correctly timed insemination coincided and that progesterone remained above $4 \mathrm{ng} / \mathrm{ml}$ for $>20$ days. If progesterone was $>4 \mathrm{ng} / \mathrm{ml}$ for $>30$ days after conception then pregnancy was assumed to be established. The progesterone diagnosis proved to be more accurate than the rectal palpation and indicated that $36.5 \%$ of clinical diagnoses were incorrect. At 42 days postpartum $92 \%$ of cows were cycling normally which reinforces the view that identification of the oestrus cycle is the problem. Williams and Esslemont (1993) reported ovulation detection rates of $98 \%$ using progesterone assay.

\section{Oestrus: biosensors for progesterone}

The term biosensor is loosely used to describe a number of different devices, the objectives of which are to identify specific complex biological molecules by a change in electrical or opto-electronic signal. A biosensor system consists of a sensor, a system to interrogate it and a microcomputer to convert the electrical signal into a format to be displayed to an operator or computer program. The sensing methods are usually based on a monoclonal antibody, which is specific to the compound being detected. A review of systems suitable for agricultural applications was conducted by Velasco-Garcia and Mottram (2003).

Koelsch et al. (1994) reported a method of detecting progesterone with a quartz crystal micro-balance device. A crystal with a known natural frequency of oscillation was coated with an antibody which bound to progesterone when exposed to it (quartz crystal microbalance (QCM)). Since the mass of the progesterone binding to the antibody would change the frequency at which the crystal oscillated, the degree of binding could be determined by measuring a change in oscillation. The device was dipped into a solution of progesterone and then exposed to air and the change in oscillation monitored. However, there have been no further reports of work on this device. Claycomb and Delwiche (1998) showed that realistic levels of progesterone would only produce a change in mass of $0.4 \%$ on a QCM very close to the noise level of the microelectronics they proposed an alternative method by automating an ELISA test for on-line measurement of progesterone in bovine milk and detection of oestrus. The biosensor used an enzyme immunoassay format for molecular recognition, which was developed to run in $\sim 8 \mathrm{~min}$. The sensor was designed to operate on-line in a dairy parlour using microinjection pumps and valves for fluid transport, fibre optics and photodiodes for light measurement, and a control computer for sequencing. Calibration showed a dynamic response between 0.1 and $5 \mathrm{ng} / \mathrm{ml}$ progesterone in milk.

Pemberton et al. (1998) reported a device was based on a disposable screen-printed amperometric progesterone biosensor, operated in a competitive immunoassay. The biosensor comprised a monoclonal anti-progesterone antibody $(\mathrm{mAb})$ immobilised on the working area of a screen-printed carbon electrode (SPCE). It relied upon a reduction in the binding of alkaline phosphatase-labelled progesterone in the presence of endogenous milk progesterone. The enzyme substrate was naphthyl phosphate and the 1-naphthol generated in the enzymatic reaction was electrochemically oxidised, producing a signal inversely proportional to the concentration of unlabelled progesterone in milk. This SPCEbased immunosensor for progesterone was incorporated into a thin-layer flow cell offering advantages such as on-line analysis and improved fluid handling with the possibility of future automation (Pemberton et al., 2001). Velsco-Garcia and Mottram (2001) built an online progesterone monitoring system. The system was based on applying a milk sample to an electrochemical biosensor and reading the electrical response.

A commercial venture between Foss Electric and de Laval developed the Herd Navigator system, which has been on sale since 2008. It combines automated sampling and five sensing systems including progesterone in milk. Scientific reports are limited as yet. Blom and Ridder (2010) reported that heat detection rates of $95 \%$ to $97 \%$ were being achieved on three farms in Denmark with days open reduced by 20 days in the $1^{\text {st }}$ year of operation. Pregnancy rates also increased significantly in a very short time: up to $50 \%$. Herd Navigator automatically measures the level of progesterone in milk, software indicates insemination time, lists animals for final pregnancy confirmation, indicates early abortion and lists the cows with risk for cysts and prolonged anoestrus. Vreeburg (2010) reported heat detection rates of two farms in the Netherlands using Herd Navigator was $94 \%$ and $99 \%$. Pregnancy rates of $42 \%$ and $46 \%$ were reported. Mazeris (2010) claim that a number of Herd Navigator farmers have stopped performing manual pregnancy tests and saved between $€ 250$ and $€ 350 /$ cow per year. Herd Navigator consists of a large analyser boxed with controlled environment and complex plumbing system to bring the milk samples to the analyser from the short milk tubes. It is designed to fit into 
parlours with up to eight milking points when newly installed and would be difficult to retrofit into existing parlours, particularly large systems that are working continuously.

\section{Mastitis detection}

Mastitis is an inflammatory response of the mammary gland to a challenge, usually bacterial. Mastitis can occur at any time in lactation but usually when animals are under stress and sometimes during the dry period. Mastitis detection must be done during milking to enable contaminated milk to be separated before it enters the food supply chain and to treat the disease in a timely manner. The challenge in mastitis detection is that each pathogen causes a different inflammatory response. A traditional role for humans at milking is to detect mastitic milk by detection of clots, behavioural changes and swollen or heated udders. Robotic milking requires sensor technology to achieve the same results. Robotic milking is standardised by ISO 20966 (ISO, 2007) but the requirement to detect abnormal milk is only described in Annex C (Informative). There is as yet no definitive method that covers all inflammatory responses so many systems are in development. Helgren and Reinemann (2006) reviewed the methods commonly in use in automated milking, colour change and conductivity with associated algorithms. Reinemann and Helgren (2004), concluded that robotics 'provide sufficient information for motivated dairy producers' to achieve national milk quality standards. Milk quality standards for mastitis are expressed in somatic cell count (SCC) which is measured in laboratories from a bulk milk sample. The California milk test (CMT) can measure cell count cowside, it uses a reagent which disrupts the cell membrane of somatic cells present in the milk sample; the DNA in those cells react with the test reagent by changing the viscosity of the test solution. It has been used successfully as a manual cowside test since the 1970s and has been automated as CellSense ${ }^{\mathrm{TM}}$ and offered as an option on milking systems by LICAutomation (2015). Neitzel et al. (2014) tested sensors for CMT and showed that the significant between sensor variation could be improved by a different calibration method. A different method is used in the DeLaval online cell counter (DeLaval, Tumba, Stockholm County, Sweden, 2015) where a reagent is mixed with a subsample of milk to enable an image capture system to count cell nuclei. The cost of reagents militates against the cell counting tests being used at every milking but can be deployed when other indications (conductivity, discolouration, temperature rise, behavioural changes) require validation. Conductivity has been used to detect some mastitis since the 1970s (GebreEgziabher et al., 1979) but it lacks sensitivity and specificity to all inflammatory responses. Conductivity is attractive as an engineering system since it needs no reagents and can be cleaned in place. An array of conductive sensors with different cross sensitivities was used by Mottram et al. (2007). A total of 67 samples of milk from both mastitic and healthy glands were measured. It was demonstrated that the multisensor system could distinguish between control and clinically mastitic milk samples $(P=0.05)$. The sensitivity and specificity of the sensor system (93\% and $96 \%)$ showed an improvement over conductivity (56\% and $82 \%$ ). The multisensor system offers a novel method of improving mastitis detection. Sloth et al. (2003) demonstrated that a multivariate approach (milk yield, protein percentage, fat percentage, lactose percentage, citrate percentage, SCC and two electrical conductivity parameters included 821 cowlevel observations) can detect udder conditions and aid udder health.

As endotoxin bacterial infections progress very rapidly towards severe illness and even death, systems are necessary to detect sub-clinical signs and behavioural change (Siivonen et al., 2011) and thermal imaging of udders (Hovinen et al., 2008) have been demonstrated to have potential particularly in robotic situations. Mastitis detection is still developing but the complexity of the disease and the need to develop non-antibiotic treatments mean that innovation is continuing. The main approach is to use conductivity, behavioural change and may be thermal imaging to detect developing sub-clinical conditions and then to confirm diagnosis with an SCC test which may be online.

\section{Metabolic disorders}

Monitoring nutrition has become more important as grazing systems have been supplemented and even completely displaced by stored feeds. Traditionally milk yield and composition, BW and body condition score (BCS) have been used to identify the success of a feeding program but these systems have a long feedback loop and homoeostasis causes the cow to adjust her output to the ration offered. Measuring rumen $\mathrm{pH}$ is a direct way of ensuring that there is a balance between the behavioural routines of the cow and the nutritional requirements of the rumen flora (Mottram, 1997).

\section{Metabolic disorders: rumen sensing}

Methods for measuring ruminal $\mathrm{pH}$ in commercial cows were based on either rumenocentesis or through use of an oral sampling tube (Tajik and Nazifi, 2011). Both methods are invasive and can only gain one data point from an imprecise location within the rumen. Direct measurement of the rumen $\mathrm{pH}$ by wireless telemetry was reported by Mottram et al. (2008). Rumen pH is known to be highly variable in time, with up to $2.5 \mathrm{pH}$ range through the day and varying spatially up to $0.5 \mathrm{pH}$ units from top to bottom within the rumen (Gasteiner et al., 2010). The wireless telemetry bolus allows continuous recording of data from a fixed location within the rumen-reticulum, thereby overcoming the variability in data. The boluses measure $\mathrm{pH}$ and/or temperature and store the data for download on demand. Some boluses download data when the cow passes fixed monitoring stations; others use a handheld device to enable a human to download while inspecting the cow. The chief limitations of the technology are that boluses are too expensive to be used on every cow and have short lives due to $\mathrm{pH}$ sensor poisoning. Boluses 
with ion-selective field-effect transistor $\mathrm{pH}$ sensors appear to degrade faster than those using glass electrodes. The technology is too new to determine whether it will have a major market impact but in small studies it appears to show that estimations of acidosis incidence based on rumenocentesis (Atkinson, 2013) are too high. The wealth of data these boluses provide has yet to be integrated into mainstream nutritional thinking, which may have been too conservative in the past. Rumen boluses have also been sold to measure temperature only, these are considerably cheaper than $\mathrm{pH}$ sensors but do suffer from a lack of models as to how data can be used. Rose-Dye et al. (2011) showed that temperature boluses detected infection challenge in steers.

\section{Metabolic disorders: weight and body condition}

As lactation progresses the BCS changes along with the weight of the cow first falling then rising. Auto-weighing is offered by a number of manufacturers as a standard accessory for milking parlour exits and walk through passages linked to EID. A different approach is to instrument the floor of the robot to detect weight. Alawneh et al. (2011) showed that daily variability (SD $17 \mathrm{~kg}$ ) of weight could be overcome by taking an 8 day rolling mean. The standard deviation of daily live weight (LW) measurements across parities was $17 \mathrm{~kg}$, on average. A near perfect association between LW measured statically and walk over (concordance correlation coefficient $0.99,95 \% \mathrm{Cl} 0.99$ to 1.0$)$ was observed and recommended that LW are recorded on a daily basis to allow changes in physiological status such as the onset of acute illness or oestrus to be detected in a 7 day management review.

An alternative approach is to measure BCS using image processing. This has the potential benefit that cameras are inherently cheaper and simpler to maintain than mechanical weigh cells. Bewley et al. (2008) were able to show a good correlation between BCS and digitally processed static images. Anglart (2014) was able to show a good correlation between automatically captured digital images and weight on Swedish Red cows but had difficulties with black and white pigmented cows. An alternative approach by Halachmi et al. (2013) was immune from pigmentation by using thermal imaging showing a Pearson correlation of 0.94 with manual BCS.

\section{Calving detection}

The transition from dry to lactating through calving is the most dangerous time of the cows annual cycle needing careful management. Being able to better predict the time of calving would enable prophylactic measures to adjust diets and management to reduce problems. Although the mean length of gestation can be added to the insemination date to predict the date of parturition, the sex and breed of the foetus and other variables mean that there is usually a wide distribution around the predicted date (Matthews and Morton, 2012). Parturition is initiated by the foetus and there are few physiological indicators in the dry state that can be measured and research has focused on behavioural data as the cow herself senses the onset of calving. Miedema (2010) showed that changes in a 'restlessness' index counting the number of times a cow changed from lying to standing and the reverse in the final $6 \mathrm{~h}$ before calving (appearance of contractions) can be used to detect the onset of calving when compared with the individual cow's 'restlessness' index during the dry period 21 days before calving. Rutten et al. (2014) found that a model based on measures of rumination, activity and temperature on 417 calvings were predictive but with high false positive and negatives. Maltz et al. (2011) showed that measurement of lying time, number of steps, number of lying bouts and movement through the barn could be modelled to predict calving time up to $48 \mathrm{~h}$ before calving with $90 \%$ true positives although there were $15.6 \%$ false alarms. One pragmatic approach is to insert a vaginal temperature detection bolus, when calving starts the bolus drops out causing a major temperature change which sets off an alarm (Medria, 2015). Insertion of devices into the vagina may raise risk of infection and still needs a timely intervention and may only be appropriate for high value animals at risk of dystocia.

During calving, the contractions can be detected by electrohysterogram measurement with a belt strapped around the cows hind quarters on which were mounted adapted ECG probes (unpublished, Author's collection). Calving detection is an area where new technology could still be developed to show a major benefit on farms.

\section{Mobility and lameness measurement}

Lameness has come to the fore as a major problem in the dairy sector and a means of informing the herd management and supply chain as to issues in any given herd has become a priority. Mobility score was developed as a manual tool to aid in classifying herd lameness and identifying trends. However, manual systems are inherently subjective and widely criticised. A number of approaches have been tried to automate mobility scoring (walk over load cells, leg load during milking, back posture with three-dimensional (3D) cameras, dynamic analysis, behavioural analysis and time of passage). A major problem in this area is the relatively low number of lame cows (mobility score 3 or more) and the need for statistical strength given the larger number of low mobility score cows. Varner et al. (2001) patented a system where a cow walks over grid of load cells which measures forces and algorithms map these data to produce a lameness score automatically. The system has been available commercially as Stepmetrix and was tested by Bicalho et al. (2007), in two studies conducted to evaluate visual locomotion scoring and Stepmetrix locomotion scoring in detecting painful digit lesions. When performed by trained veterinarians, visual locomotion scoring performed better than Stepmetrix in detecting cows with painful lesions. Pastell and Kujala (2007) used load cells in a robotic milker with 37 cow scores to measure leg load during milking and classified $96.2 \%$ correctly as mobility score $(0,1,2)$ against lame (mobility score 3 or above). When a cow's mobility 
score increases the cows back arches and Viazzi et al. (2013) compared two imaging methods to measure the degree of arching. Two-dimensional imaging needs an unobscured view of the flank of a single cow and this is hard to achieve in practice on farms and so a 3D approach using the low cost Kinect camera developed for games playing was tried. The accuracy of the two systems in detecting arched backs was comparable at 90\%. Van Hertem et al. (2013) used existing data sources from milking and activity monitors to discriminate between 44 lame and 74 sound animals. A logistic regression model was developed based on the seven highest correlated model input variables (the daily milk yield 4 days before diagnosis; the slope coefficient of the daily milk yield 4 days before diagnosis; the nighttime to daytime neck activity ratio 6 days before diagnosis; the milk yield week difference ratio 4 days before diagnosis; the milk yield week difference 4 days before diagnosis; the neck activity level during the daytime 7 days before diagnosis; the ruminating time during nighttime 6 days before diagnosis). After a 10 -fold cross-validation, the model obtained a sensitivity of 0.89 and a specificity of 0.85 , with a correct classification rate of 0.86 demonstrated that existing farm data can detect clinically lame animals. A much larger study by Kamphuis et al. (2013), on nearly 4904 milkings of grazing cows with 292 lame cows measuring weight, milking parameters and pedometers concluded that detection performance was not sufficiently accurate for commercial use. The real requirement for the industry is not just to detect lameness but also detect sub-clinical changes in mobility score so that interventions can be made earlier. Mottram and Bell (2010) showed that capturing the time taken for an individual cow to pass along a passage is closely correlated to the 5-point mobility score. As long as the cows are allowed to walk at their own speed the higher mobility score cows took longer to proceed through a raceway. A follow-up study by Martinez-Ortiz et al. (2013) showed that the speed of cows could be measured by remote video tracking by segregating cows even in wide races which would make EID speed monitoring difficult. There are thus a number of options for measuring lameness and even mobility score and this is an area for exciting future developments.

\section{Summary and conclusions}

This review has focused on technologies to detect those conditions (fertility, metabolic disorders, mastitis and lameness) and that cost the cows pain and economic loss. For fertility monitoring, oestrus detection collar systems have become widely adopted and are replacing pedometers but do not offer the added capabilities of the new technology of on-line progesterone analysis to detect infertility and pregnancy as well as ovulation. Metabolic disorder monitoring has been enhanced by the development of rumen wireless telemetry to detect sub-acute acidosis, automated weighing and more promisingly BCS by image capture although in 2015 this is not yet available as an automatic tool. Mastitis detection has been developed such that a low cost screening by conductivity and behavioural analysis can be enhanced by automated SCC to validate diagnosis. Lameness detection has advanced with products on the market but mobility scoring has not yet been routinely achieved. Technology developments are following two diverse strands, one is to load more sensors onto the animal, particularly onto collars. This means that the sensors can be monitoring the animal continuously wherever she is. The other approach which is inherently cheaper, particularly for large herds, is to have a single monitoring position close or at the milking system through which all cows must pass. The robotic milker with its high number of individual cow contacts daily is an ideal place to conduct such individual cow monitoring. This area of technology is developing rapidly and techniques are sometimes tried which have no validity in the biological indicators.

\section{Acknowledgements}

This work was partly funded by BBSRC, UK Follow on Fund grant 2013-2014 and Royal Society of Edinburgh Enterprise Fellowship, 2015. Editing and referencing by Jack Worfolk of eCow Devon Ltd, Exeter, UK, EX1 1BH.

\section{References}

Alawneh Jl, Stevenson MA, Williamson NB, Lopez-Villalobos N and Otley T 2011. Automatic recording of daily walkover liveweight of dairy cattle at pasture in the first 100 days in milk. Journal of Dairy Science 94, 4431-4440.

Anglart D 2014. Automatic estimation of body weight and body condition score in dairy cows using 3D imaging technique. Retrieved March 15, 2015, from http://stud.epsilon.slu.se/6355/1/anglart_d_140114.pdf

Anonymous/LICAutomation 2015. CellSense - SCC test, identify mastitis - LIC automation. Retrieved November 16, 2015, from http://www.licautomation. com/products/cellsense/

Atkinson 0 2013. A cross-sectional survey to investigate prevalence of and clinical indicators for Subacute Ruminal Acidosis (SARA) in lactating cows on UK dairy farms. Dissertation for RCVS DCHP. Retrieved November 16, 2015, from http://www.dairyveterinaryconsultancy.co.uk/pdfs/Sub\%20acute\%20ruminal\% 20acidosis-\%20Dissertation.pdf

Bewley JM, Boehlje MD, Gray AW, Hogeveen H, Kenyon SJ, Eicher SD and Schutz MM 2010. Stochastic simulation using @Risk for dairy business investment decisions. Agricultural Finance Review 70, 97-125.

Bewley JM, Peacock A, Lewis O, Boyce R, Roberts D, Coffey P, Kenyon S and Schutz M 2008. Potential for estimation of body condition scores in dairy cattle from digital images. Journal of Dairy Science 91, 3439-3453.

Bicalho RC, Cheong SH, Cramer G and Guard Cl 2007. Association between a visual and an automated locomotion score in lactating Holstein cows. Journal of Dairy Science 90, 3294-3300.

Blanchard T, Kenney D, Garcia M, Kristula M, Wolfer J and Haenlein G 1987. Relationship of declines in grain consumption and milk-yield to estrus in dairycattle. Theriogenology 28, 407-415.

Blazquez NB, French JM, Long SE and Perry GC 1988. A pheromonal function for the perineal skin glands in the cow. Veterinary Record 123, 49-50.

Blom JY and Ridder C 2010. Reproductive management and performance can be improved by use of de Laval Herd Navigator, First North American Conference on Precision Dairy Management, Toronto, Canada.

Boyd $\mathrm{H}$ 1992. Estrus and estrous cycles: problems and failures. In Bovine medicine (ed. AH Andrews, RW Blowey, H Boyd and EG Eddy), pp. 433-448. Blackwell Science, Oxford, England.

Claus R, Karg H, Zwiauer D, von Butler I, Pirchner F and Rattenberger E 1983. Analysis of factors influencing reproductive performance of the dairy cow by progesterone assay in milk-fat. British Veterinary Journal 139, 29-37.

Claycomb RW and Delwiche MJ 1998. Biosensor for on-line measurement of bovine progesterone during milking. Biosensors and Bioelectronics 13, 1173-1180. 
Darwash AO and Lamming GE 1996. The importance of progesterone levels during early pregnancy in the cow. Proceedings of Nottingham Cattle Fertility Conference, Nottingham University, pp. 1-4.

Frost AR, Schofield CP, Beaulah SA, Mottram TTF, Lines JA and Wathes CM 1997. A review of livestock monitoring and the need for integrated systems. Computers and Electronics in Agriculture 17, 139-159.

Future Dairy 2012. Heat detection research. Retrieved March 15, 2015, from http://adf.farmonline.com.au/news/magazine/equipment-and-technology/technology/heat-detection-research/2639984.aspx on.

Gasteiner J, Fallast M, Rosenkranz S, Häusler J, Schneider K, Guggenberger T 2010. Measuring rumen $\mathrm{pH}$ and temperature by an indwelling and wireless data transmitting unit and application under different feeding conditions. Berline und Münchner Tierärztliche Wochenschrift 123, 406-412.

Gebre-Egziabher A, Wood HC, Robar JD and Blankenagel GJ 1979. Evaluation of automatic mastitis detection equipment. Journal of Dairy Science 62, 1108-1114.

Halachmi I, Klopčič M, Polak P, Roberts DJ and Bewley JM 2013. Automatic assessment of dairy cattle body condition score using thermal imaging. Computers and Electronics in Agriculture 99, 35-40.

Helgren JM and Reinemann DJ 2006. Survey of milk quality on U.S. dairy farms utilizing automatic milking systems. Transactions of the American Society of Agricultural and Biological Engineers 49, 551-556.

Hempstalk K, Burke CR and Kamphuis C 2013. Verification of an automated camera-based system of oestrus detection in dairy cows. Proceedings of the New Zealand Society of Animal Production, vol. 73, Hamilton, pp. 26-28.

Hovinen M, Siivonen J, Taponen S, Hänninen L, Pastell M, Aisla A-M and Pyörälä S 2008. Detection of clinical mastitis with the help of a thermal camera. Journal of Dairy Science 91, 4592-4598.

Hurnik JF, Webster AB and DeBoer S 1985. An investigation of skin temperature differentials in relation to estrus in dairy cattle using a thermal infrared scanning technique. Journal of Animal Science 61, 1095-1102.

ISO 20966:2007. Automatic milking installations - Requirements and testing.

Kamphuis C, DelaRue B, Burke CR and Jago J 2012. Field evaluation of 2 collarmounted activity meters for detecting cows in estrus on a large pasture-grazed dairy farm. Journal of Dairy Science 95, 3045-3056.

Kamphuis C, Frank E, Burke JK, Verkerk GA and Jago JG 2013. Applying additive logistic regression to data derived from sensors monitoring behavioral and physiological characteristics of dairy cows to detect lameness. Journal of Dairy Science 96, 7043-7053.

Kiddy CA, Mitchell DS and Hawk HW 1984. Estrus-related odors in body fluids of dairy cows. Journal of Dairy Science 67, 388-391.

Klemm WR, Hawkins GN and De Los Santos E 1987. Identification of compounds in bovine cervico-vaginal mucus extracts that evoke male sexual behavior. Chemical Senses 12, 77-87.

Klemm WR, Rivard GF and Clement BA 1994. Blood acetaldehyde fluctuates markedly during bovine estrous cycle. Animal Reproduction Science 35, 9-26.

Koelsch RK, Aneshansley DJ and Butler WR 1994. Analysis of activity measurement for accurate estrus detection in dairy-cattle. Journal of Agricultural Engineering Research 58, 107-114.

Llobet E, Hines EL, Gardner JW, Bartlett PN and Mottram TTF 1999. Fuzzy ARTMAP based electronic nose data analysis. Sensors and Actuators B 61, 183-190.

Lopez H, Caraviello DZ, Satter LD, Fricke PM and Wiltbank MC 2005. Relationship between level of milk production and multiple ovulations in lactating dairy cows. Journal of Dairy Science 88, 2783-2793.

Maatje K, deMol RM and Rossing W 1997. Cow status monitoring (health and estrus) using detection sensors. Computers and Electronics in Agriculture 16, 245-254.

Maatje K, Rossing W and Wiersma F 1987. Temperature and activity measurements for estrus and sickness detection in dairy cattle. Proceeding of $3 \mathrm{rd}$ Symposium Automation in Dairying, Wageningen, The Netherlands, September 9-11, IMAG, Mansholtlaan 10-12, pp. 176-184.

MacArthur AJ, Easdon MP and Gregson K 1992. Milk temperature and detection of estrus in dairy cattle. Journal of Agricultural Engineering Research 51, 29-46.

Maltz E, Medini N, Bercovitch A, Parmet Y, Halachmi I, Antler A and Edan Y 2011. Predicting calving time of dairy cows by behaviour sensor. In European Conference on Precision Livestock Farming (ed. C Lokhorst and D Berckmans), pp. 464-475. Czech Centre for Science and Society, Prague, Czech Republic.
Martinez-Ortiz CA, Everson RM and Mottram TTF 2013. Video tracking of dairy cows for assessing mobility scores. Joint European Conference on Precision Livestock Farming, 10-12 September, Leuven, Belgium.

Matthews BJ and Morton JM 2012. Accuracy of predicted calving dates in Holstein-Friesian dairy cows based on fetal ages estimated using manual rectal palpation. New Zealand Veterinary Journal 60, 234-240.

Mazeris F 2010. DeLaval Herd Navigator proactive herd management. The first North American conference on precision dairy management. Toronto, Canada, 2-5 March.

McLeod BJ and Williams ME 1991. Incidence of ovarian dysfunction in post partum dairy cows and the effectiveness of its clinical diagnosis and treatment. Veterinary Record 128, 121-124.

Medria 2015. Vel'Phone - service for detecting calving. Retrieved August, 2015, from http://www.medria.fr/en_GB/produits/vel-phone.html

Miedema H 2010. Investigating the use of behavioural, accelerometer and heart rate measurements to predict calving in dairy cows. PhD thesis, University of Edinburgh. Retrieved March 31, 2015, from https://www.era.lib.ed.ac.uk/ bitstream/handle/1842/6502/Miedema2010.pdf;jsessionid=5AE2BBCCC2150F6 D8BF24ACB7CDD9686? sequence $=2$

Mitchell RS, Sherlock RA and Smith LA 1996. An investigation into the use of machine learning for determining estrus in cows. Computers and Electronics in Agriculture 15, 195-213.

Mottram TTF 1997. Automatic monitoring of the health and metabolis status of dairy cows. Livestock Production Science 48, 209-217.

Mottram TTF and Bell NJ 2010. A novel method of monitoring mobility of dairy cows. In Proceedings of the First North American Conference on Precision Dairy Management, Toronto, Canada, pp. 182-183.

Mottram TTF, Lark RM, Lane A, Wathes DC, Persaud KC, Swan M and Cooper JM 2000. Techniques to allow the detection of oestrus in dairy cows with an electronic nose. Electronic noses and olfaction. In Proceedings of the 7th International Symposium on Olfaction and Electronic Noses, Brighton, UK (ed. JW Gardner and KC Persaud), pp. 201-208. Institute of Physics, Bristol, UK. Mottram TTF, Lowe J, McGowan M and Phillips N 2008. Technical note: a wireless telemetric method of monitoring clinical acidosis in dairy cows. Computers and Electronics in Agriculture 64, 45-48.

Mottram TTF, Rudnitskaya A, Legin A, Fitzpatrick JL and Eckersall PD 2007. Evaluation of a novel chemical sensor system to detect clinical mastitis in bovine milk. Biosensors and Bioelectronics 22, 2689-2693.

Nebel RL 1988. On-farm milk progesterone tests. Journal of Dairy Science 71, 1682-1690.

Neitzel A-C, Stamer E, Junge W and Thaller G 2014. Calibration of an automated California mastitis test with focus on the device-dependent variation. Springerplus 3, 760.

Pastell ME and Kujala M 2007. A probabilistic neural network model for lameness detection. Journal of Dairy Science 90, 2283-2292.

Pemberton RM, Hart JP, Foulkes JA 1998. Development of a sensitive, selective electrochemical immunoassay for progesterone in cow's milk based on a disposable screen-printed amperometric biosensor. Electrochim Acta 43, 3567-3574. Pemberton RM, Hart JP, Mottram TTF 2001. An electrochemical immunosensor for milk progesterone using a continuous flow system. Biosensors and Bioelectronics 16, 715-723.

Peter AT and Bosu WTK 1986. Postpartum ovarian activity in dairy-cows correlation between behavioural estrus, pedometer measurements and ovulations. Theriogenology 26, 111-115.

Peters AR and Ball PJH 1995. Reproduction in cattle, second edition. Blackwell Science.

Reinemann DJ and Helgren JM 2004. Online milk sensing issues for automatic milking. Proceedings for the ASAE/CSAE, Ottawa, Canada, August 2014, Paper No. 04-4191.

Rose-Dye TK, Burciaga-Robles LO, Krehbiel CR, Step DL, Fulton RW, Confer AW and Richards CJ 2011. Rumen temperature change monitored with remote rumen temperature boluses after challenges with bovine viral diarrhea virus and Mannheimia haemolytica. Journal Animal Science 89, 1193-1200.

Rutten CJ, Steeneveld W, Kamphuis C and Hogeveen H 2014. The potential of using sensor data to predict the moment of calving for dairy cows. Proceedings of 65th Annual Meeting of the EAAP, August, Copenhagen.

Schofield SA 1988. Oestrus in dairy cows. Technical Report, Dairy Research Unit, University College of North Wales, UK. 


\section{Mottram}

Schofield SA, Phillips CJC and Owens AR 1991. Variation in the milk-production activity rate and electrical-impedance of cervical-mucus over the estrus period of dairy cows. Animal Reproduction Science 24, 231-248.

Senger PL 1994. The estrus detection problem: new concepts, technologies and possibilities. Journal of Dairy Science 77, 2745-2753.

Siivonen J, Taponen S, Hovinen $M$, Pastell $M$, Lensink B-J, Pyörälä $S$ and Hänninen L 2011. Impact of acute clinical mastitis on cow behaviour. Applied Animal Behaviour Science 132, 101-106.

Sloth KHMN, Friggens NC, Løvendahl P, Andersen PH, Jensen J and Ingvartsen $\mathrm{KL}$ 2003. Potential for Improving description of bovine udder health status by combined analysis of milk parameters. Journal of Dairy Science 86, 1221-1232.

Stevenson JS, Smith MW, Jaeger JR, Corah LR and Lefever DG 1996. Detection of estrus by visual observation and radiotelemetry in peripubertal estrus- synchronized beef heifers. Journal of Animal Science 74, 729-735.

Tajik J and Nazifi S 2011. Diagnosis of subacute ruminal acidosis: a review. Asian Journal of Animal Sciences 5, 80-90.

Van Hertem T, Maltz E, Antler A, Bites Romanini C, Viazzi S, Bahr C, SchlageterTello A, Lokhorst C, Berckmans D and Halachmi I 2013. Lameness detection based on multivariate continuous sensing of milk yield, rumination, and neck activity. Journal of Dairy Science 96, 4286-4298.

Van Vliet JH and Van Eerdenburg FJCM 1996. Sexual activities and oestrus detection in lactating Holstein cows. Applied Animal Behaviour Science 50, 57-69.
Varner M, Tasch U, Erez B and Lefcourt AM 2001. Method and apparatus for detecting lameness in animals. Patent Application No. US20020055691 A1.

Velasco-Garcia MN and Mottram TTF 2001. Biosensors in the livestock industry: an automated ovulation prediction system for dairy cows. Trends in Biotechnology 19, 433-434.

Velasco-Garcia MN and Mottram TTF 2003. Biosensor technology addressing agricultural problems. Biosystems Engineering 84, 1-12.

Viazzi S, Bahr C, Schlageter-Tello A, Van Hertem T, Bites Romanini C, Pluk A, Halachmi I, Lokhorst C and Berckmans D 2013. Analysis of individual classification of lameness using automatic measurement of back posture in dairy cattle. Journal of Dairy Science 96, 257-266.

Voronin V, Brayer E and Ben-Menachem U 2011. Method and device for detecting estrus, May 26. Patent Application No. 20110125065.

Vreeburg N 2010. Precision management on two Dutch dairy farms by use of Herd Navigator. First North American Conference on Precision Dairy Management, Toronto, Canada.

Warren ME 1984. Biological targets for fertility and their effects on herd economics. In Dairy cow fertility (ed. RJ Eddy and MJ Ducker), pp. 1-14. British Veterinary Association, London, England.

Williams ME and Esslemont RJ 1993. A decision support system using milk progesterone tests to improve fertility in commercial dairy herds. Veterinary Record 132, 503-506. 